\title{
Heave Motion Measurement by Adaptive Filter Based on Longuet-Higgins Wave Model
}

\author{
Jiazhen Lu, Qiuwei Luo, and Yanqiang Yang \\ School of Instrumentation Science \& Opto-Electronics Engineering, Beihang University (BUAA), 37 XueYuan Road, Haidian District, \\ Beijing 100191, China \\ Correspondence should be addressed to Jiazhen Lu; ljzbuaa@163.com
}

Received 13 September 2016; Accepted 7 February 2017; Published 28 February 2017

Academic Editor: Alberto Borboni

Copyright (C) 2017 Jiazhen Lu et al. This is an open access article distributed under the Creative Commons Attribution License, which permits unrestricted use, distribution, and reproduction in any medium, provided the original work is properly cited.

A method is proposed to obtain heave motion information based on the Longuet-Higgins wave model. The Longuet-Higgins wave model which is closer to the sea wave is introduced. Based on it, random process of the noise is analyzed and the highpass filter is designed to reduce errors. Then it is the key point in this article that an adaptive algorithm is put forward because of the complexity of the waves. The algorithm adjusts the cutoff frequency to reduce the amplitude attenuation of the filter by analyzing the wave. For the same reason the comprehensive parameter of the phase compensation can be also obtained by the algorithm. Simulation measurement results show that under the rough sea situation the maximum value of absolute error is $0.4942 \mathrm{~m}$ according to the normal method, the method is $0.1170 \mathrm{~m}$, and the average error ratio of the rough sea test reduces to $3.89 \%$ from $12.54 \%$, which demonstrates that the adaptive filter is more effective in measuring heave movement. A variety of simulation cases show that the adaptive filter can also improve the precision of the heave motion under different sea situations.

\section{Introduction}

Heave motion is generally used in the research of floating offshore engineering. For example, the introduction of heave information is beneficial for ship replenishment, landing of shipboard aircraft, and the design of heave compensation of offshore oil drilling platform. Moreover, the measurement of heave motion is used to provide a reference for the safety of vessels sailing. For example, "sheng lu" ship capsized due to the factor of the storm in 1991.

How to get heave information has been mentioned in many studies. Basically there are two main types of filtering methods for heave motion. One is the Kalman filter. For example, El-Hawary estimated heave component with Kalman filtering which established a handled value [1]. Triantafyllou et al. used Kalman filtering techniques to estimate the ship motion [2]. Aminzadeh and El-Hawary used the Generalized Kalman to solve the problem of heave compensation in underwater applications [3]. Fossen and Perez introduced the ship motion-control models and used Kalman filter to eliminate the oscillatory [4]. But the method has two main drawbacks. One drawback is that the model of the heave dynamics cannot be equivalent to the actual model. The other drawback is that Kalman filtering requires GPS or other external reference information. However, the result of GPS height is not accurate enough to compute heave motion value. In this paper according to the requirment of navigation system design, a long time pure inertial navigation is desired, so Kalman filter is not applicable in this case.

The other type is the highpass filter. For example, in the 1990s, an adaptive filter algorithm for heave motion was developed by Godhavn and was implanted in the seatex MRU [5]. Yang et al. did active heave compensation experiments to validate the validity of active heave compensation system in 2008 [6]. Simulations and the tests with MTi unit were done by Yang et al. and the results have proven that the adaptive highpass filter was effective in 2009 [7]. Wei and Feng used highpass filter to eliminate Schuler errors to get heave information in 2012 [8]. Hu and Tao put forward the weighted-frequency Fourier linear combiner algorithm for phase compensation in 2013 [9]. However, little attention has been focused on the sea wave model which decides the cutoff frequency of the filter. It is often assumed that the wave model is a simple sine function. In fact, ship motion in waves is a 
complex random process as a result of sea tides, currents, and wind effects.

In order to get accurate heave motion which is based on strapdown inertial navigation system (SINS) composed of inertial sensors with high accuracy, it is necessary to select a sea model which can better reflect the actual situation to analysis. Thus, this paper chooses the Longuet-Higgins wave model which is closer to the actual situation and analyzes the random process of the narrowband noise. On the basis of this analysis, an algorithm is proposed to adjust the cutoff frequency to reduce the amplitude error caused by the filter. In addition, the same algorithm is used to change all pass system parameters to compensate phase error.

The structure of this paper is given as follows. In Section 2 the Longuet-Higgins wave model and the accelerometer error model are introduced to analyze the noise. In Section 3, the method is presented and analyzed. Moreover, the steps of heave measurement are shown. Simulation measurement results are given in Section 4. Finally, the article ends with concluding remarks in Section 5.

\section{Review and Analysis}

Referring to previous literatures, the sea model and the inertial unit error model [10-12] are set up. In addition, the correlated noise is analyzed based on the model.

\subsection{Mathematical Model}

2.1.1. Longuet-Higgins Wave Model. In order to describe the characteristics of the actual wave, Longuet-Higgins wave model is established on the basis of the measurement data [13]. According to the assumption of the model, the wave motion is a random process. The fixed point fluctuation of the wave is composed of some different phases and different amplitude sine wave.

The wave surface displacement is expressed as

$$
\eta(t)=\sum_{n=1}^{\infty} a_{n} \cos \left(w_{n} t+\varepsilon_{n}\right) .
$$

In the equation above, $a_{n}$ and $w_{n}$ are the amplitude and frequency of the $n$th wave component, respectively, $t$ represents time, and $\varepsilon_{n}$ is the random phase uniformly distributed in the $(0,2 \pi)$. Furthermore, the sea wave only has a dominant component under most condition.

2.1.2. Inertial Unit Error Model. The accelerometer error model is given as follows [14]:

$$
\begin{aligned}
E_{a}= & n+k_{0}+k_{i} G_{i}+k_{i i} G_{i}^{2}+k_{i i i} G_{i}^{3}+k_{i o} G_{i} G_{o} \\
& +k_{i p} G_{i} G_{p},
\end{aligned}
$$

where $E_{a}$ is the accelerometer error, $n$ is the white Gaussian noise, $k_{0}$ is a constant bias, $k_{i}$ is linear error coefficient, $k_{i i}$, $k_{i i i}$ are, respectively, second-order and third-order nonlinear error coefficient, and $k_{i o}, k_{i p}$ are cross-axis coupling coefficient, respectively. $G_{i}, G_{0}$, and $G_{p}$ are, respectively, the specific force of input axis, output axis, and pendulum axis.
The relationship of two models is given as follows:

$$
\ddot{\eta}=T \cdot\left(A-E_{a}\right),
$$

where $A$ is the measured value of accelerometers; $T$ is coordinate transformation matrix of SINS.

On the other hand, the gyroscope error contains the constant error and random drift. Affected by inertial unit errors, the coordinate transformation matrix $T$ is not accurate. When SINS works for a long time, the 6-degree-offreedom navigation results are in oscillation because of incorrect $T$. According to the error analysis of SINS, under the undamped case the results include three kinds of different cycles of persistent oscillation [15]. They are, respectively, Schuler oscillation period $T_{s}$, earth oscillation period $T_{e}$, and Foucault oscillation period $T_{F}$.

$$
\begin{aligned}
& T_{s}=2 \pi \sqrt{\frac{R}{g}} \approx 84.8 \mathrm{~min}, \\
& T_{e}=\frac{2 \pi}{\Omega}=24 \mathrm{~h}, \\
& T_{F}=\frac{2 \pi}{\Omega \sin \varphi},
\end{aligned}
$$

where $R$ is the earth radius; $\Omega$ is self-rotation angle velocity of the earth; $\varphi$ is latitude; $g$ is gravitational acceleration. Foucault oscillation period decreases with increased latitude. In addition, the period of earth oscillation and the period of Foucault oscillation are greater than the period of the heave motion, so this paper mainly considers the effects of Schuler oscillation for heave motion measurement.

2.1.3. Highpass Filter. Schuler oscillation whose period is $84.8 \mathrm{~min}$ in the process of SINS is caused by the constant bias of inertial sensors with high accuracy. The existence of Schuler oscillation makes heave information divergent. The frequency of Schuler oscillation is less than the frequency of heave motion. The highpass filter is designed to eliminate Schuler oscillation and reduce noise [16].

In this paper a fourth-order highpass filter is given by the following equation:

$$
H_{s}=\frac{\eta}{\iint(A) d t d t}=\frac{s^{4}}{\left(s^{2}+2 \xi w_{c} s+w_{c}^{2}\right)^{2}},
$$

where $\xi=1 / \sqrt{2}$ is the damping factor, $s$ is the Laplace variable, and $w_{c}$ is the cutoff frequency of the highpass filter which can be tuned.

2.2. Analysis of Narrowband Noise. Due to the influence of random phase of the wave, the high order nonlinear error part sensed by the accelerometer can be equivalent to a narrowband noise after two integrations [17]. The white Gaussian noise is also in the form of narrowband noise in the heave information because of the output with a range of sampling frequency. The random process of narrowband noise in the wave model is discussed as follows. 
Without considering the impact of other errors which are the constant bias and linear errors of the accelerometer, narrowband noise in the random phase wave model is analyzed. The model can be expressed as follows:

$$
Y(t)=\iint(A) d t d t \approx \eta(t)+N(t),
$$

where $\eta(t)$ is the sine wave with the random phase

$$
\begin{aligned}
\eta(t) & =\operatorname{acos}\left(w_{0} t+\beta\right) \\
& =a \cos \beta \cos w_{0} t-a \sin \beta \sin w_{0} t,
\end{aligned}
$$

where $a$ is the known amplitude, $\beta$ is the random phase uniformly distributed in the $(0,2 \pi)$, and $w_{0}$ is the known angular frequency.

In (5), narrowband noise $N(t)$ is a narrowband stationary Gaussian random process. The mean is zero and the variance is $\sigma^{2}$. It is given as follows:

$$
\begin{aligned}
N(t) & =Q(t) \cos \left[w_{0} t+\varphi_{n}(t)\right] \\
& =Q_{c}(t) \cos w_{0} t-Q_{s}(t) \sin w_{0} t .
\end{aligned}
$$

According to (6) and (7), (5) is rewritten as

$$
\begin{aligned}
Y(t) & =B_{c}(t) \cos w_{0} t-B_{s}(t) \sin w_{0} t \\
& =B(t) \cos \left[w_{0} t+\Phi(t)\right] .
\end{aligned}
$$

In the equation above,

$$
\begin{aligned}
& B_{c}(t)=a \cos \beta+Q_{c}(t), \\
& B_{s}(t)=a \sin \beta+Q_{s}(t), \\
& B(t)=\left[B_{c}^{2}(t)+B_{s}^{2}(t)\right]^{1 / 2}, \\
& \Phi(t)=\arctan \frac{Q_{s}(t)}{Q_{c}(t)} .
\end{aligned}
$$

Under the condition of a given signal phase $\theta$ and the time of $t$, with the value range of $B$ and $\theta$ being $B \geq 0, \theta \leq 2 \pi$, the probability density function of the envelope is given by

$$
p(B \mid \theta)=\frac{B}{\sigma^{2}} \exp \left\{-\frac{a^{2}+B^{2}}{2 \sigma^{2}}\right\} I_{0}\left(\frac{a B}{\sigma^{2}}\right) \quad B \geq 0,
$$

where $I_{0}\left(a B / \sigma^{2}\right)$ is the zero-order Bessel function and $a B / \sigma^{2}$ is the number of Bessel functions.

Assuming that $b=a / \sigma, v=B / \sigma,(10)$ can be expressed as

$$
p(v)=\frac{v}{\sigma} \exp \left\{-\frac{1}{2}\left(v^{2}+b^{2}\right)\right\} I_{0}(b v) \quad v \geq 0 .
$$

In the actual situation, the useful signal of the accelerometer is much larger than the noise; therefore, $b v \geq 1$

$$
\begin{aligned}
p(v) & \approx \frac{v}{\sigma} \exp \left\{-\frac{1}{2}\left(b^{2}+v^{2}\right)\right\} \frac{1}{v b \sqrt{2 \pi}} \exp \{b v\} \\
& \approx \frac{1}{\sigma \sqrt{2 \pi}} \exp \left\{-\frac{1}{2}(v-b)^{2}\right\} .
\end{aligned}
$$

With $B \approx a$ and $v=b$, the mean and variance of $B(t)$ are given by

$$
\begin{aligned}
& E[B(t)]=a, \\
& D[B(t)]=\sigma^{2} .
\end{aligned}
$$

However, some of frequency of the noise is the same as frequency of heave motion. So the important thing is to select the appropriate cutoff frequency of the filter to minimize errors.

\section{Design and Error Analysis of Adaptive Algorithm}

According to Section 2, it is important to design the filter to get the heave information. While there are the phase errors and the amplitude attenuation in the filter, it is necessary to compensate them.

3.1. Adaptive Phase Compensation of Filter. The peak to peak error which is induced by the filter is presented as follows:

$$
\left|1-\left\|H_{s}\right\|\right|=\left|1-\frac{w^{4}}{w^{4}+w_{c}^{4}}\right|=\frac{w_{c}^{4}}{w^{4}+w_{c}^{4}} \longrightarrow\left(\frac{w_{c}}{w}\right)^{4}
$$

for $w \gg w_{c}$.

From (14), the peak to peak error cannot be ignored. Phase compensation is realized to reduce the peak to peak error by using first-order all pass system in this paper $[18,19]$. It is given by

$$
H_{p}(z)=\frac{z^{-1}-k}{1-k z^{-1}} \quad 0<|k|<1 .
$$

The amplitude response of the system is not affected by the frequency so that all frequency components of the input signal can be passed without amplitude attenuation. The phase error caused by the filter can be compensated by choosing the appropriate $k$ value.

Then the $z$ plane is mapped to the $s$ plane through the expression $z=e^{s T}$, so

$$
z=\frac{2 / T+s}{2 / T-s}
$$

With (15) and (16), we can get

$$
H_{p}(s)=\frac{s-(2-2 k) / T(1+k)}{-s-(2-2 k) / T(1+k)} .
$$

In (17), $T$ is the sampling period.

By multiplying the highpass filter $H_{f}(j w)$ and the all pass system $H_{p}(j w)$, the expression is given as follows:

$$
H(j w)=H_{f}(j w) \cdot H_{p}(j w) .
$$

$w$ is the frequency of the heave motion. By making the phase zero, we can determine the parameter $k$ value. But the heave 
motion is composed of several different phase waves. So with comprehensive consideration, an adaptive algorithm is proposed to select the parameter to minimize the phase error.

$$
K=\frac{1}{\sum_{n=1}^{N} a_{n}} \sum_{n=1}^{N}\left(a_{n} k_{n}\right)
$$

where $K$ is the comprehensive parameter; $a_{n}$ is the amplitude of the $n$th wave component of the sea, and $k_{n}$ is the phase compensation parameter of the $n$th wave.

3.2. Adaptive Selection of The Cutoff Frequency. The amplitude attenuation of the filter is given by

$$
\begin{aligned}
&\left\|1-H_{s}\right\|=\frac{\sqrt{w_{c}^{8}+8 w^{6} w_{c}^{2}}}{w^{4}+w_{c}^{4}} \longrightarrow 2 \sqrt{2}\left(\frac{w_{c}}{w}\right) \\
& \text { for } w \gg w_{c} .
\end{aligned}
$$

The magnitude of errors is closely related to the cutoff frequency and the input frequency of the filter. Furthermore, according to analysis of narrowband noise, the variance of $B(t)$ is $\sigma^{2}$, so the narrowband noise error is given as follows:

$$
E\left(\bar{\eta}_{n}^{2}(t)\right)=\frac{1}{2 \pi} \int_{-\infty}^{\infty}\left|H_{s}(j w)\right|^{2} \sigma^{2} d w=\frac{2^{-7 / 2} \sigma^{2}}{w_{c}^{3}} .
$$
follows:

The magnitude of the errors and the noise are given as

$$
\begin{aligned}
E\left[\left(\bar{\eta}^{2}(t)\right)\right] & =f\left(w_{c}, a, w, \sigma\right) \\
& \leq \frac{2^{-7 / 2} \sigma^{2}}{w_{c}^{3}}+8 a^{2}\left(\frac{w_{c}}{w}\right)^{2} .
\end{aligned}
$$

According to the change of the frequency $w$, selecting the optimal cutoff frequency $w_{c}$ minimizes the magnitude of errors. The method is given by

$$
\begin{aligned}
E\left(w_{c}\right) & =E\left(\bar{\eta}^{2}(t)\right), \\
\frac{\partial E\left(w_{c}\right)}{\partial w_{c}} & =0, \\
w_{c} & =\left(\frac{0.0166 \sigma^{2} w^{2}}{a^{2}}\right)^{1 / 5} .
\end{aligned}
$$

Only with one frequency of the signal, a single optimal cutoff frequency can be obtained by (24). However, the heave motion is composed of some sine waves. Therefore, on this basis, an adaptive algorithm is proposed to find the comprehensive optimal cutoff frequency. It is given by

$$
W_{c}=\frac{\sum_{n=1}^{N}\left(a_{n} w_{c n}\right)}{\sum_{n=1}^{N} a_{n}},
$$

where $W_{c}$ is the comprehensive optimal cutoff frequency and $w_{c n}$ represents the single optimal cutoff frequency of the $n$th wave component of the sea wave.

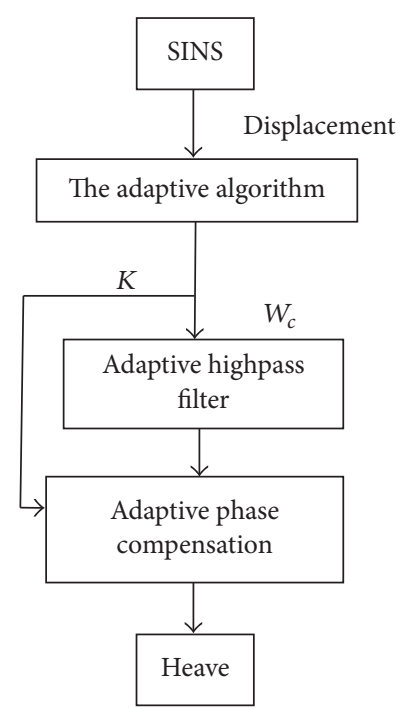

FIgURE 1: The steps of heave measurement.

3.3. Error Analysis. The method can estimate heave motion, but there still exist errors at heave information. It is necessary to analyze range of errors. So

$$
E\left(P^{2}(t)\right) \leq \sum_{n=1}^{N}\left[\frac{2^{-7 / 2} \sigma^{2}}{W_{c}^{3}}+8 a^{2}\left(\frac{W_{c}}{w_{n}}\right)^{2}\right] .
$$

In the above equation, $w_{n}$ is the frequency of the $n$th wave component. They are determined by the sea wave. Even though the sea wave motion is changing, the range of error can be obtained by (26).

3.4. The Steps of Heave Measure. The steps of heave measure are shown in Figure 1. Firstly, the displacement of altitude channel is calculated by SINS. Secondly, the frequency and the amplitude of each wave component are obtained by FFT spectrum analysis. Next, the comprehensive parameter $K$ and the comprehensive optimal cutoff frequency $W_{c}$ are, respectively, calculated by the adaptive algorithm. Finally, the heave motion information can be obtained by the adaptive filter and phase compensation.

\section{Simulation and Measurement Results}

Experiments based on the Longuet-Higgins wave model are performed to validate the effectiveness of the adaptive algorithm. To simulate different sea conditions, the model is built by the computer simulation. It is assumed that the latitude is $30^{\circ}$ and the longitude is $120^{\circ}$. The constant error and random drift of the gyroscope are, respectively, $0.01^{\circ} / \mathrm{h}$ and $0.005^{\circ} /(\mathrm{h} \cdot \sqrt{\mathrm{Hz}})$. The constant error of the accelerometer is $100 \mathrm{ug}$ and the random drift is $80 \mathrm{ug} /(\mathrm{h} \cdot \sqrt{ } \mathrm{Hz})$.

4.1. Simulation Test under Certain Sea Condition. To get closer to the actual sea vessel heave motion, the simulation of true heave motion based on the Longuet-Higgins wave model is implemented. What is more, in order to 
TABLE 1: Four-group simulation experiments.

\begin{tabular}{|c|c|c|c|c|c|}
\hline $\begin{array}{l}\text { Simulation } \\
\text { number }\end{array}$ & $\begin{array}{c}\text { Cutoff } \\
\text { frequency }\end{array}$ & $\begin{array}{l}\text { Maximum value of } \\
\text { absolute error }(\mathrm{m})\end{array}$ & $\begin{array}{l}\text { Average value of errors } \\
(\mathrm{m})\end{array}$ & $\begin{array}{c}\text { Standard deviation of } \\
\text { errors }(\mathrm{m})\end{array}$ & Error ratio (\%) \\
\hline \multirow{2}{*}{1} & $w_{c}$ & 0.4925 & -0.0370 & 0.1869 & 16.37 \\
\hline & $W_{c}$ & 0.1226 & $-2.877 e-05$ & 0.0453 & 4.076 \\
\hline \multirow{2}{*}{2} & $w_{c}$ & 0.5006 & -0.0367 & 0.1868 & 16.64 \\
\hline & $W_{c}$ & 0.1206 & $6.709 e-05$ & 0.0453 & 4.009 \\
\hline \multirow{2}{*}{3} & $w_{c}$ & 0.4929 & -0.0367 & 0.1872 & 16.39 \\
\hline & $W_{c}$ & 0.1181 & $3.548 e-05$ & 0.0453 & 3.926 \\
\hline \multirow{2}{*}{4} & $w_{c}$ & 0.5000 & -0.0369 & 0.1871 & 16.62 \\
\hline & $W_{c}$ & 0.1263 & $6.872 e-05$ & 0.0453 & 4.199 \\
\hline
\end{tabular}

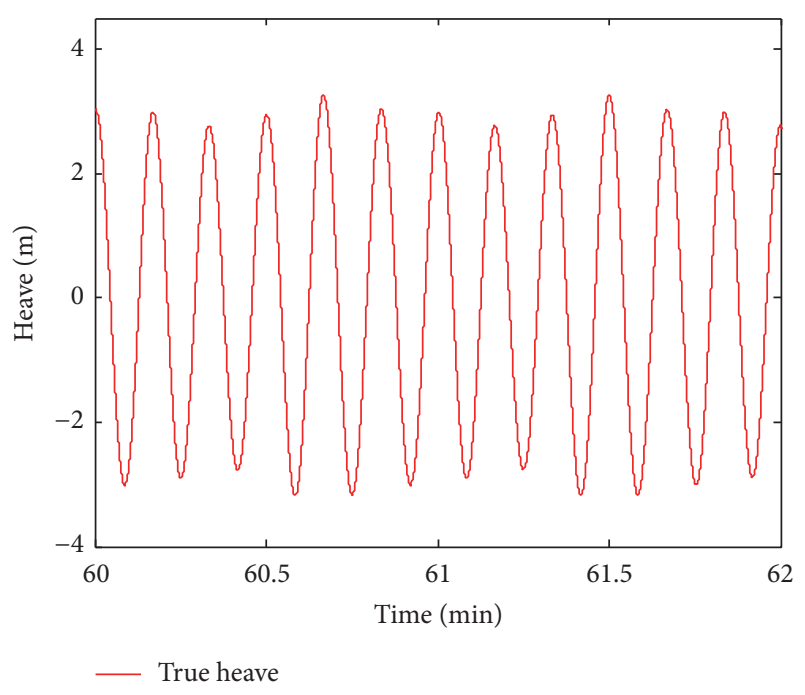

FIGURE 2: Simulation of true heave motion.

confirm the adaptive algorithm's effectiveness, the single optimal cutoff frequency $w_{c}$ and the comprehensive optimal cutoff frequency $W_{c}$ are, respectively, selected as the cutoff frequency of the filter to estimate heave motion information.

The Sea Model Setup. The main frequency of true heave motion is $0.1 \mathrm{~Hz}$ and the amplitude is $3 \mathrm{~m}$; others are $0.14 \mathrm{~Hz}, 0.1 \mathrm{~m} ; 0.08 \mathrm{~Hz}, 0.2 \mathrm{~m} ; 0.15 \mathrm{~Hz}, 0.02 \mathrm{~m} ; 0.07 \mathrm{~Hz}$, $0.01 \mathrm{~m} ; 0.15 \mathrm{~Hz}, 0.008 \mathrm{~m} ; 0.06 \mathrm{~Hz}, 0.009 \mathrm{~m} ; 0.011 \mathrm{~Hz}, 0.005 \mathrm{~m}$; $0.09 \mathrm{~Hz}, 0.002 \mathrm{~m}$, and so on. According to Longuet-Higgins wave model, the wave is composed of much trigonometric function, but the amplitude or energy of much wave component is low, so they can be ignored. The simulation of the sea wave is shown in Figure 2.

In Figure 3, the cutoff frequency of the filter is the single optimal cutoff frequency $w_{c}$. In Figure 4 , the cutoff frequency of the filter is the comprehensive optimal cutoff frequency $W_{c}$.

According to (24), the single optimal cutoff frequency of the dominate wave component of the heave movement is obtained $w_{c}=0.0168 \mathrm{rad} / \mathrm{s}$. As shown in Figure 3, the black line represents filtered but uncompensated heave, the blue line represents filtered and compensated heave, and the red line represents the true value of the heave simulation. After filtering, the maximum error is $0.4942 \mathrm{~m}$, the average value is $-0.0372 \mathrm{~m}$, and the standard deviation is $0.1874 \mathrm{~m}$. The error ratio that the maximum error is divided by the amplitude of the heave is $16.43 \%$. There is a big error by comparing the black with the red and only a little amplitude error by comparing the blue with the red.

As shown in Figure 4, the comprehensive optimal cutoff frequency $w_{c}=0.0198 \mathrm{rad} / \mathrm{s}$ is obtained from (25). The maximum error is $0.1170 \mathrm{~m}$, the average value is $8.929 e-05 \mathrm{~m}$, and the standard deviation is $0.0453 \mathrm{~m}$. The error ratio is $3.89 \%$. We can see that the blue line almost coincides with the red line.

By comparing two simulation experiment results, the maximum error has been reduced by $0.3772 \mathrm{~m}$. The average value has been almost $0 \mathrm{~m}$. The standard deviation has been reduced to $0.0453 \mathrm{~m}$. The error ratio has been reduced by $12.54 \%$. It is clear that the results of the comprehensive optimal cutoff frequency are superior to the results of the single optimal cutoff frequency in this case.

According to wave model, the phase of the wave component is a random process. Four-group simulation experiments with different phases are conducted to validate the proposed algorithm. The maximum error, the average value, the standard deviation, and the error ratio are shown in Table 1 according to the single and the comprehensive optimal cutoff frequency. The experiments show that the adaptive algorithm is also suitable for the different phases in the same case.

4.2. Test Results under Different Sea Cases. Considering different sea states, the waves are divided into three types which are, respectively, rough sea, moderate sea, and slight sea, respectively. The amplitude range of rough sea is $2 \mathrm{~m}$ to $3 \mathrm{~m}$. The amplitude range of moderate sea is $1 \mathrm{~m}$ to $2 \mathrm{~m}$. The amplitude range of slight sea is $0 \mathrm{~m}$ to $1 \mathrm{~m}$. Therefore, three tests are conducted to validate the validity of the adaptive algorithm under different sea height circumstances.

Test 1 . The model of rough sea is built that the main frequency of true heave motion is $0.1 \mathrm{~Hz}$ and the amplitude is $2.5 \mathrm{~m}$; others are $0.08 \mathrm{~Hz}, 0.15 \mathrm{~m}$, and $0.14 \mathrm{~Hz}, 0.1 \mathrm{~m}$. 


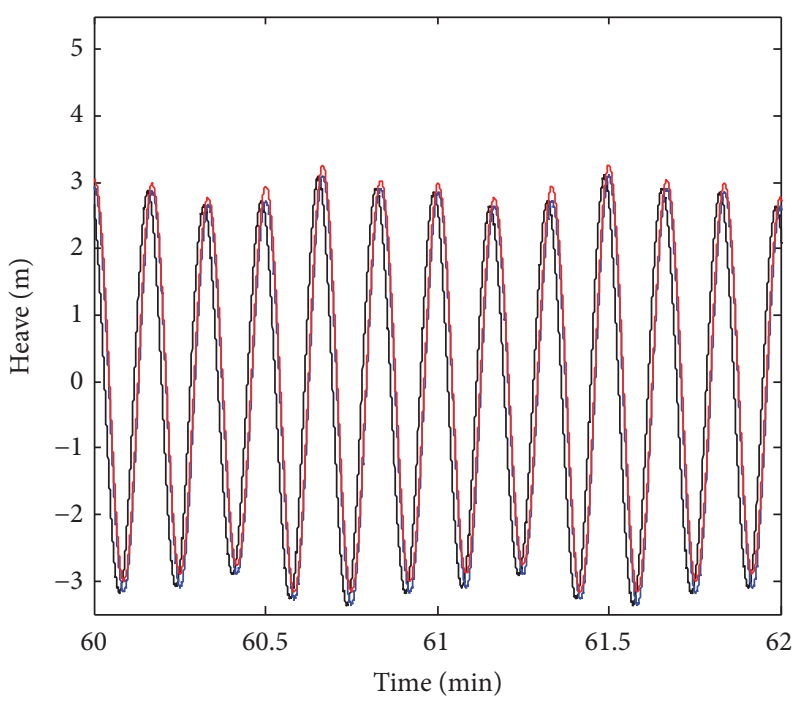

- Filtered and uncompensated heave
- Filtered heave

- True heave

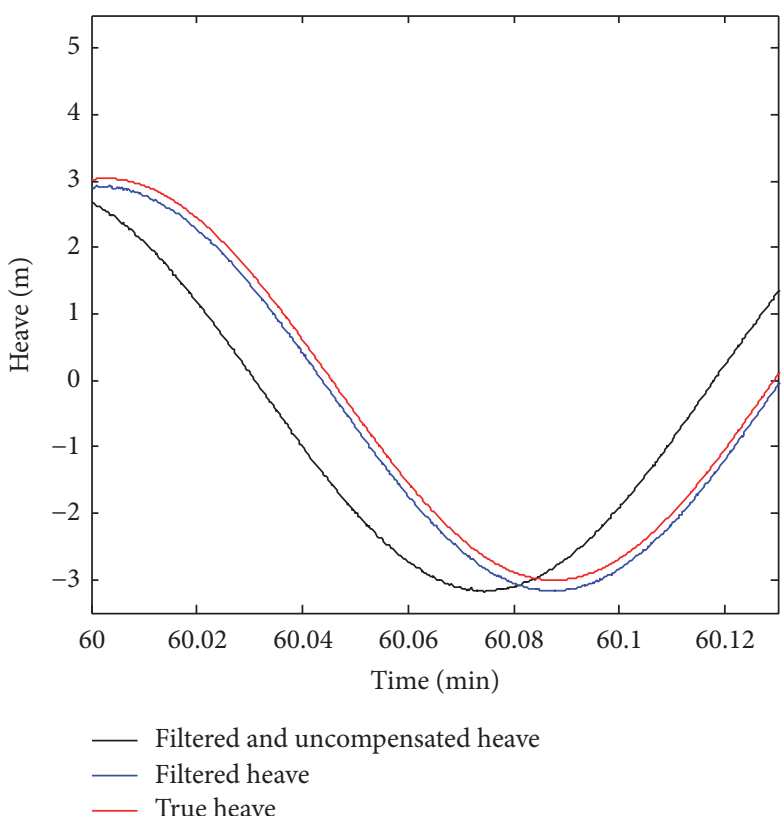

FIGURE 3: Measurement with the single optimal cutoff frequency.
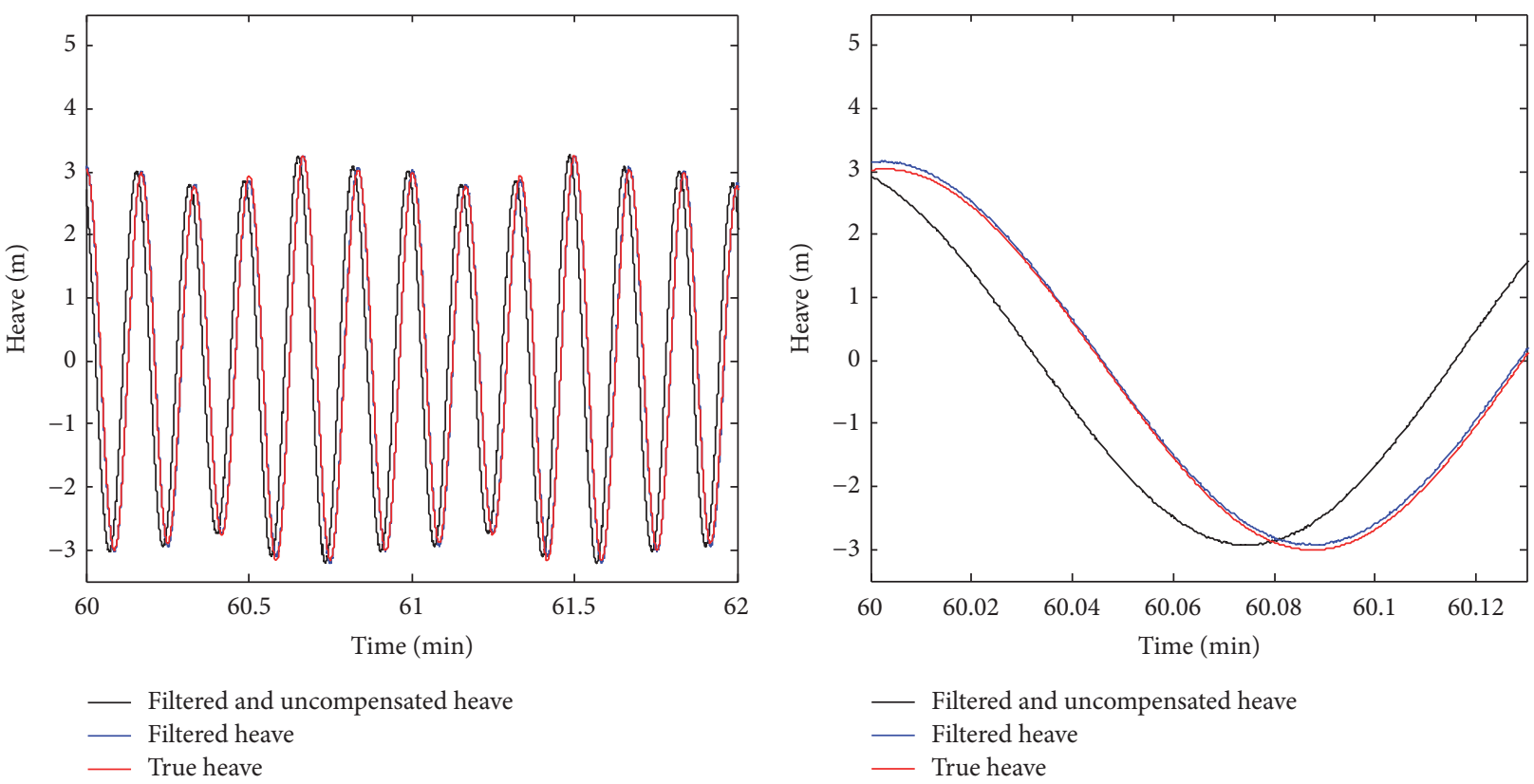

FIGURE 4: Measurement with the comprehensive optimal cutoff frequency.

Test 2. The model of moderate sea is built that the main frequency of true heave motion is $0.1 \mathrm{~Hz}$ and the amplitude is $1.6 \mathrm{~m}$; others are $0.08 \mathrm{~Hz}, 0.05 \mathrm{~m}$, and $0.14 \mathrm{~Hz}$, $0.05 \mathrm{~m}$.

Test 3. The model of slight sea is built that the main frequency of true heave motion is $0.1 \mathrm{~Hz}$ and the amplitude is $0.6 \mathrm{~m}$; others are $0.08 \mathrm{~Hz}, 0.02 \mathrm{~m}$, and $0.14 \mathrm{~Hz}, 0.01 \mathrm{~m}$.

Tables 2, 3, and 4 are, respectively, the measurement results of Test 1, Test 2, and Test 3 .
As Table 2 shows, the average error ratio of the rough sea test reduces to $4.855 \%$ from $11.70 \%$. As Table 3 shows, the average error ratio of the moderate sea test reduces to $5.255 \%$ from $16.12 \%$. As Table 4 shows, the average error ratio of the slight sea test reduces to $9.527 \%$ from $39.42 \%$. Furthermore, the maximum error, the average value, and the standard deviation obviously have decreased by the adaptive algorithm in all tests.

The measure results show that the adaptive algorithm is effective in getting better accuracy estimation of heave 
TABLE 2: Rough sea test.

\begin{tabular}{|c|c|c|c|c|c|}
\hline $\begin{array}{l}\text { Simulation } \\
\text { number }\end{array}$ & $\begin{array}{c}\text { Cutoff } \\
\text { frequency }\end{array}$ & $\begin{array}{l}\text { Maximum value of } \\
\text { absolute error }(\mathrm{m})\end{array}$ & $\begin{array}{l}\text { Average value of errors } \\
(\mathrm{m})\end{array}$ & $\begin{array}{c}\text { Standard deviation of } \\
\text { errors }(\mathrm{m})\end{array}$ & Error ratio (\%) \\
\hline \multirow{2}{*}{1} & $w_{c}$ & 0.2945 & 0.0182 & 0.0971 & 11.74 \\
\hline & $W_{c}$ & 0.1181 & $1.326 e-05$ & 0.0422 & 4.712 \\
\hline \multirow{2}{*}{2} & $w_{c}$ & 0.2969 & 0.0184 & 0.0975 & 11.85 \\
\hline & $W_{c}$ & 0.1257 & $3.084 e-05$ & 0.0422 & 5.015 \\
\hline \multirow{2}{*}{3} & $w_{c}$ & 0.2865 & 0.0182 & 0.0974 & 11.43 \\
\hline & $W_{c}$ & 0.1193 & $2.117 e-05$ & 0.0422 & 4.760 \\
\hline \multirow{2}{*}{4} & $w_{c}$ & 0.2948 & 0.0185 & 0.0974 & 11.76 \\
\hline & $W_{c}$ & 0.1236 & $2.117 e-05$ & 0.0422 & 4.931 \\
\hline
\end{tabular}

TABLe 3: Moderate sea test.

\begin{tabular}{|c|c|c|c|c|c|}
\hline $\begin{array}{l}\text { Simulation } \\
\text { number }\end{array}$ & $\begin{array}{c}\text { Cutoff } \\
\text { frequency }\end{array}$ & $\begin{array}{l}\text { Maximum value of } \\
\text { absolute error }(\mathrm{m})\end{array}$ & $\begin{array}{l}\text { Average value of errors } \\
(\mathrm{m})\end{array}$ & $\begin{array}{l}\text { Standard deviation of } \\
\text { errors }(\mathrm{m})\end{array}$ & Error ratio (\%) \\
\hline \multirow{2}{*}{1} & $w_{c}$ & 0.2601 & 0.0183 & 0.0924 & 16.24 \\
\hline & $W_{c}$ & 0.0852 & $-3.007 e-05$ & 0.0235 & 5.320 \\
\hline \multirow{2}{*}{2} & $w_{c}$ & 0.2582 & 0.0186 & 0.0928 & 16.12 \\
\hline & $W_{c}$ & 0.0817 & $-1.140 e-5$ & 0.0235 & 5.101 \\
\hline \multirow{2}{*}{3} & $w_{c}$ & 0.2570 & 0.0186 & 0.0926 & 16.05 \\
\hline & $W_{c}$ & 0.0818 & $3.896 e-05$ & 0.0235 & 5.107 \\
\hline \multirow{2}{*}{4} & $w_{c}$ & 0.2574 & 0.0184 & 0.0921 & 16.07 \\
\hline & $W_{c}$ & 0.0881 & $-3.474 e-05$ & 0.0235 & 5.500 \\
\hline
\end{tabular}

TABLE 4: Slight sea test.

\begin{tabular}{|c|c|c|c|c|c|}
\hline $\begin{array}{l}\text { Simulation } \\
\text { number }\end{array}$ & $\begin{array}{c}\text { Cutoff } \\
\text { frequency }\end{array}$ & $\begin{array}{l}\text { Maximum value of } \\
\text { absolute error }(\mathrm{m})\end{array}$ & $\begin{array}{l}\text { Average value of errors } \\
(\mathrm{m})\end{array}$ & $\begin{array}{c}\text { Standard deviation of } \\
\text { errors }(\mathrm{m})\end{array}$ & Error ratio (\%) \\
\hline \multirow{2}{*}{1} & $w_{c}$ & 0.2387 & 0.0185 & 0.0915 & 39.76 \\
\hline & $W_{c}$ & 0.0600 & $3.552 e-04$ & 0.0134 & 9.993 \\
\hline \multirow{2}{*}{2} & $w_{c}$ & 0.2354 & 0.0182 & 0.0909 & 39.21 \\
\hline & $W_{c}$ & 0.0557 & $3.479 e-04$ & 0.0134 & 9.277 \\
\hline \multirow{2}{*}{3} & $w_{c}$ & 0.2355 & 0.0185 & 0.0910 & 39.22 \\
\hline & $W_{c}$ & 0.0548 & $3.418 e-04$ & 0.0134 & 9.127 \\
\hline \multirow{2}{*}{4} & $w_{c}$ & 0.2370 & 0.0184 & 0.0914 & 39.47 \\
\hline & $W_{c}$ & 0.0583 & $3.452 e-04$ & 0.0134 & 9.710 \\
\hline
\end{tabular}

motion under different sea cases. In addition, the error radio of the rough sea is the smallest, then followed by the error radio of the moderate sea; the worst is the error radio of the slight sea. Thus, the adaptive algorithm is more suitable for the rough sea situation.

\section{Conclusions}

This paper discusses the obtainment of the heave information by the adaptive filter. An adaptive algorithm based on the Longuet-Higgins wave model and random noise analysis is proposed to reduce the wave information errors. It adjusts the optimal cutoff frequency by analyzing the wave and is more suitable for the real ocean wave. The adaptive filter is useful to improve accuracy of heave measure under three sea states. The method in this paper is based on normal wave condition with only one primary wave. If the wave condition is very complicated especially with more than two primary waves, we need to design special filters.

\section{Competing Interests}

The authors declare that they have no competing interests.

\section{Acknowledgments}

The authors thank the Inertial Technology Key Laboratory for its support. 


\section{References}

[1] F. El-Hawary, "Compensation for source heave by use of a kalman filter," IEEE Journal of Oceanic Engineering, vol. 7, no. 2, pp. 89-96, 1982.

[2] M. S. Triantafyllou, M. Bodson, and M. Athans, "Real time estimation of ship motions using kalmanfiltering techniques," IEEE Journal of Oceanic Engineering, vol. 8, no. 1, pp. 9-20, 1983.

[3] F. Aminzadeh and F. El-Hawary, "Two dimensional generalized Kalman filter approach to heave compensation in underwater applications," in Proceedings of the Navigation; Remote Sensing; Underwater Vehicles/ Exploration (Oceans '89), pp. 1045-1048, Seattle, Wash, USA, September 1989.

[4] T. I. Fossen and T. Perez, "Kalman filtering for positioning and heading control of ships and offshore rigs," IEEE Control Systems, vol. 29, no. 6, pp. 32-46, 2009.

[5] J.-M. Godhaven, "Adaptive tuning of heave filter in motion sensor," in Proceedings of the IEEE OCEANS Conference (OCEANS '98), Nice, France, September 1998.

[6] W. Yang, Z. Zhang, and A. Zhang, "Research on an active heave compensation system for remotely operated vehicle," in Proceedings of the International Conference on Intelligent Computation Technology and Automation (ICICTA '08), pp. 407-410, Hunan, China, October 2008.

[7] Y. Wenlin, W. Sufen, Z. Zhuying, and Z. Aiqun, "Numerical simulation and testing analysis of adaptive heave motion measurements," in Proceedings of the International Conference on Measuring Technology and Mechatronics Automation (ICMTMA '09), pp. 263-266, IEEE, Hunan, China, April 2009.

[8] S. Wei and S. Feng, "Measurement technology of ship heave movement based on sins resolving," Chinese Journal of Scientific Instrument, vol. 33, no. 1, pp. 167-172, 2012.

[9] Y. Hu and L. Tao, "Real-time zero phase filtering for heave measurement," in Proceedings of the IEEE 11th International Conference on Electronic Measurement and Instruments (ICEMI '13), pp. 321-326, Harbin, China, August 2013.

[10] M. S. Longuet-Higgins, "The effect of non-linearities on statistical distributions in the theory of sea waves," Journal of Fluid Mechanics, vol. 17, no. 3, pp. 459-480, 1963.

[11] M. S. Longuet-Higgins, "On the joint distribution of the periods and amplitudes of sea waves," Journal of Geophysical Research, vol. 80, no. 18, pp. 2688-2694, 1975.

[12] W. Gao, Y. Ben, X. Zhang, Q. Li, and F. Yu, "Rapid fine strapdown ins alignment method under marine mooring condition," IEEE Transactions on Aerospace and Electronic Systems, vol. 47, no. 4, pp. 2887-2896, 2011.

[13] M. S. Longuet-Higgins, "On the joint distribution of wave periods and amplitudes in a random wave field," Proceedings of The Royal Society of London, Series A: Mathematical and Physical Sciences, vol. 389, no. 1797, pp. 241-258, 1983.

[14] C. Zhe, Principle of Strapdown Inertial Navigation System, China Astronautic, Beijing, China, 1986.

[15] W. Gao, Initial Alignment for Strapdown Inertial Navigation System, National Defence Industry Press, Beijing, China, 2014.

[16] S. K. Mitra and Y. Kuo, Digital Signal Processing: A ComputerBased Approach, McGraw-Hill, New York, NY, USA, 2006.

[17] Z. Yinqing, Random Process Theory, Beihang University Press, Beijing, China, 2013.

[18] K. Rajamani and Y.-S. Lai, "Novel method for designing allpass digital filters," IEEE Signal Processing Letters, vol. 6, no. 8, pp. 207-209, 1999.
[19] W. Latt, U.-X. Tan, K. Veluvolu, C. Shee, and W. Ang, "Realtime estimation and prediction of periodic signals from attenuated and phase-shifted sensed signals," in Proceedings of the IEEE/ASME International Conference on Advanced Intelligent Mechatronics (AIM '09), Singapore, July 2009. 


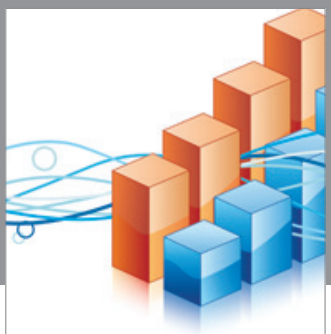

Advances in

Operations Research

vatem alat4

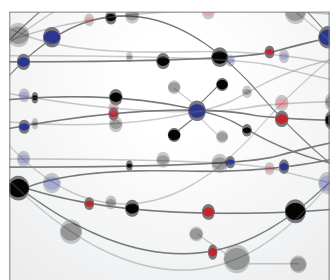

\section{The Scientific} World Journal
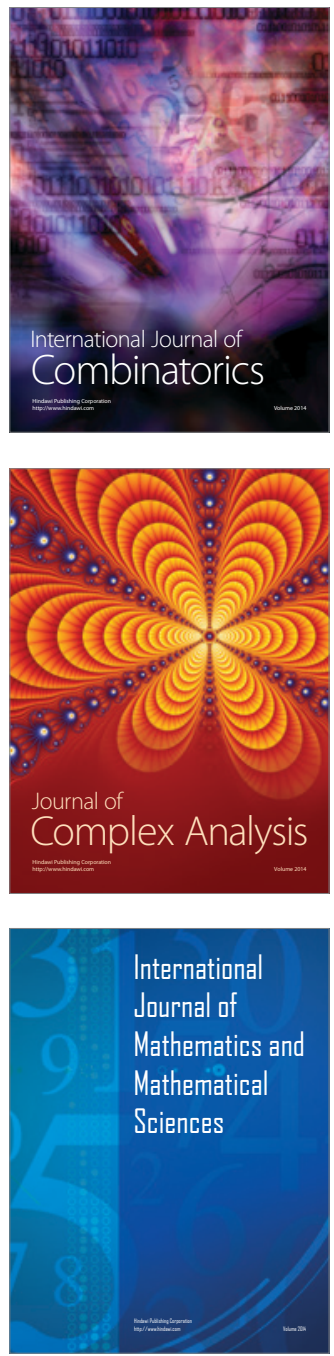
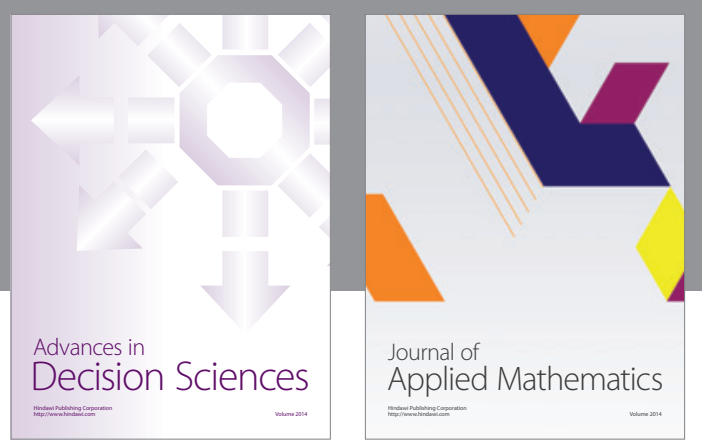

Algebra

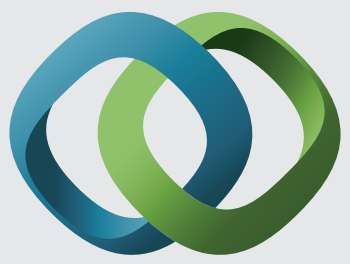

\section{Hindawi}

Submit your manuscripts at

https://www.hindawi.com
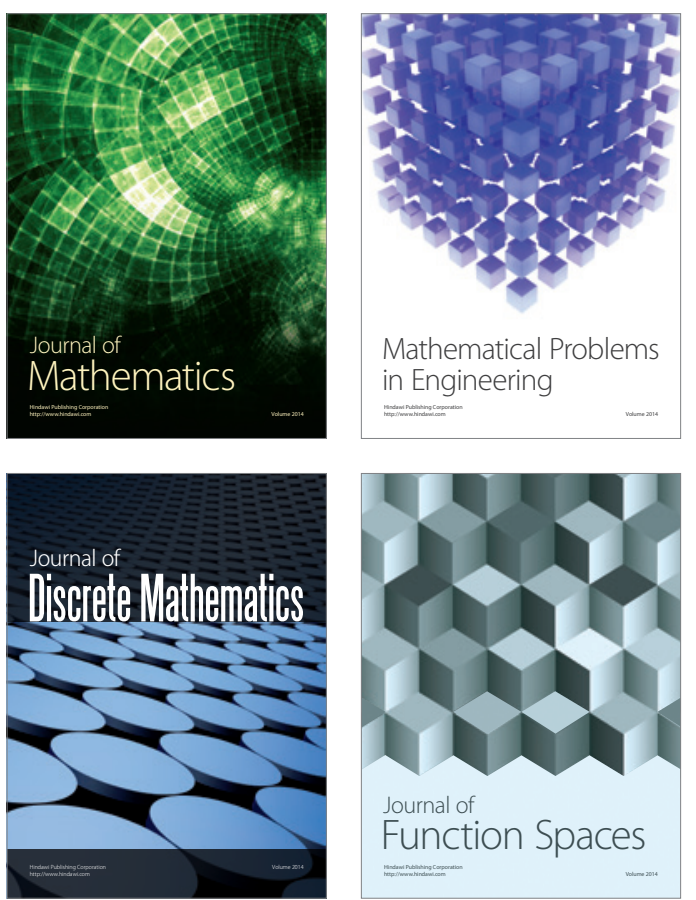

Mathematical Problems in Engineering
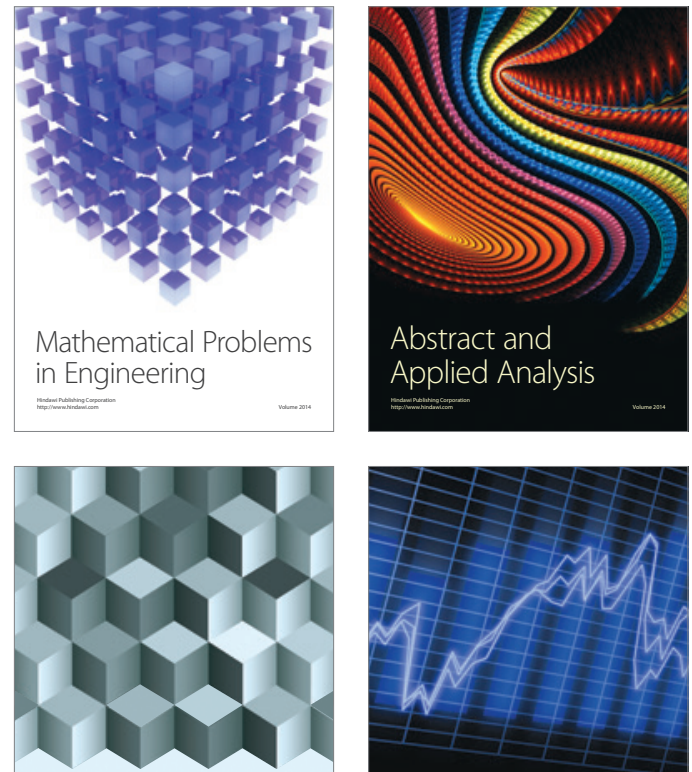

Journal of

Function Spaces

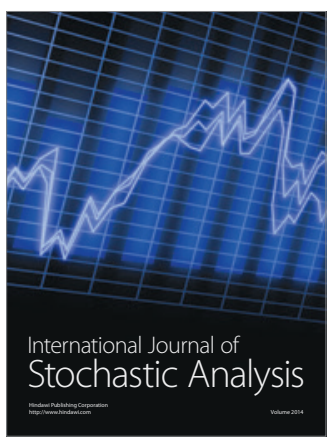

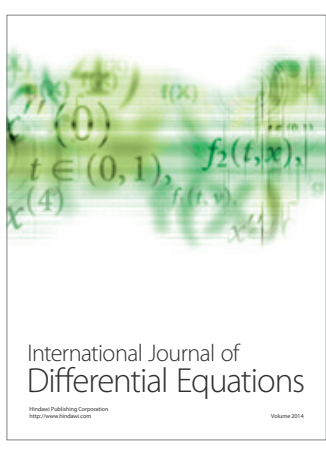
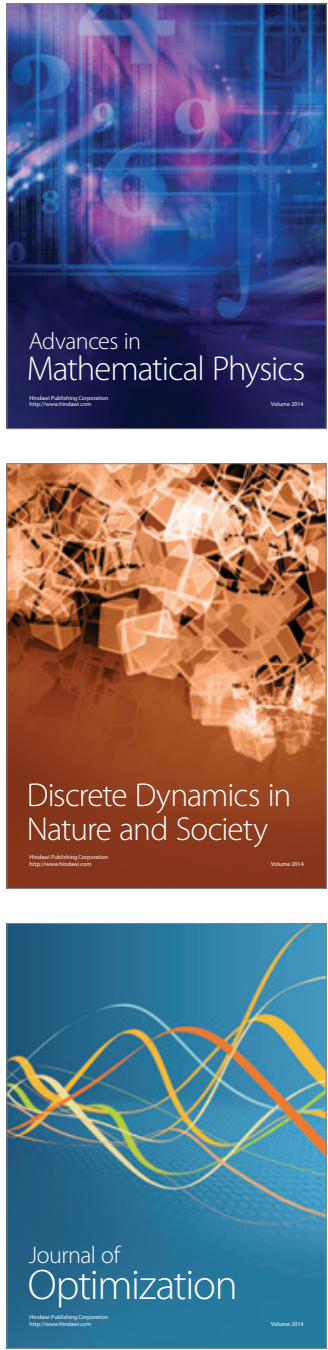